Departement für Klinische Diagnostik und Services, Abteilung für Anästhesiologie der Vetsuisse-Fakultät Universität Zürich

Vorsteherin des Departements: Prof. Dr. Regina Hofmann-Lehmann Leiterin der Abteilung für Anästhesiologie: Prof. Dr. Regula Bettschart-Wolfensberger Oberärztin der Abteilung für Anästhesiologie: PD Dr. Annette Kutter Brandau

Arbeit unter wissenschaftlicher Betreuung von Dr. Nadja Sigrist, Leiterin der Abteilung Intensivmedizin

\title{
Correlation of rotational thromboelastometry (ROTEM) parameters with platelet count and their ability to predict thrombocytopenia in dogs
}

\author{
Inaugural-Dissertation \\ zur Erlangung der Doktorwürde der \\ Vetsuisse-Fakultät Universität Zürich
}

vorgelegt von

Jennifer Turner

Tierärztin

von Kölliken, AG

genehmigt auf Antrag von

PD Dr. Annette Kutter Brandau, Referentin 



\section{Index}

Zusammenfassung

Seite 4

Abstract

Seite 5

Publiziertes Manuskript

ab Seite 6

Curriculum vitae 
Jennifer Turner

Departement für Klinische Diagnostik und Services, Abteilung Anästhesiologie gschmid@vetclinics.uzh.ch

Ziel der Studie war es die Korrelation der Plättchenzahl (PLT) mit Parametern der Rotationsthromboelastometrie (ROTEM) und ROTEM Cut-off-Werte zur Identifikation von Thrombozytopenie bei Hunden zu beschreiben.

Krankengeschichten von 113 Hunden mit parallelen EXTEM (ROTEM mit Gewebefaktor aktiviert), FIBTEM (EXTEM mit Zytochalasin D) und PLT Werten wurden retrospektiv ausgewertet. Signalement, Behandlungen vor Blutanalyse, Hämatokrit, EXTEM/FIBTEM maximale Gerinnselstärke (MCF EXTem, MCF Fiвtem) und -elastizität (MCE maximale Lyse (MLеXтем) wurden den Krankengeschichten und der Datenbank entnommen. Delta

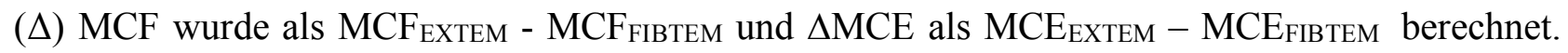
Die PLT wurden mit Spearman-Rho Analyse zu MCFextem, MCEextem, $\triangle \mathrm{MCF}$ und $\triangle \mathrm{MCE}$ korreliert. Um die Voraussagekraft des ROTEMs für Thrombozytopenie zu bestimmen wurden Receiver Operating Characteristics durchgeführt. MCF $_{\text {EXTEM }}<49 \mathrm{~mm}$, MCE EXTEM $_{293, \triangle M C F}$ $<42 \mathrm{~mm}$ und $\triangle \mathrm{MCE}<90$ sagten eine Thrombozytopenie $<60 \times 10^{9} / \mathrm{L}$ mit einer Sensitivität von 90\% und einer Spezifität von $78 \%$ voraus, mit einem negativ prädiktiven Wert von $>97 \%$ für alle 4 Parameter.

PLT korrelierten moderat aber signifikant mit allen evaluierten ROTEM Parametern. Alle Parameter konnten eine Thrombozytopenie $<60 \times 10^{9} / \mathrm{L}$ voraussagen mit einem hohen negativ prädiktiven Wert, während die Sensitivität eine Thrombozytopenie vorauszusagen moderat und der positiv prädiktive Wert tief war.

Hund, EXTEM, FIBTEM, ROTEM, Plättchenkomponente 
Vetsuisse Faculty University of Zurich (2019)

Jennifer Turner

Departement for Clinical Diagnostics and Services, Section of Anesthesiology gschmid@vetclinics.uzh.ch

Correlation of rotational thromboelastometry (ROTEM) parameters with platelet count and their ability to predict thrombocytopenia in dogs

The study objectives were to evaluate the correlation between platelet count (PLT) and rotational thromboelastometry (ROTEM) parameters and to determine ROTEM cut-off values for identification of thrombocytopenia in dogs.

Medical records of 113 dogs with concurrent EXTEM (ROTEM activated by tissue factor), FIBTEM (EXTEM with cytochalasin D) analysis and PLT were retrospectively reviewed. Signalment, treatment prior to analysis, hematocrit, EXTEM/FIBTEM maximum clot firmness (MCF EXTEM, $\mathrm{MCF}_{\text {FIBTEM}}$ ), EXTEM/FIBTEM maximum clot elasticity (MCE EXTEM, MCE $_{\text {FIBTEM}}$ ) and EXTEM maximum lysis (MLеXтем) were extracted from patient records and ROTEM database. Delta $(\Delta)$

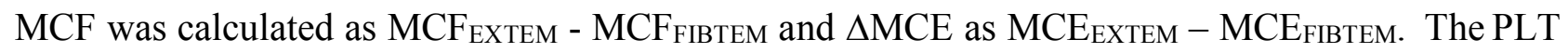
was correlated to MCF EXTEM, MCE $\mathrm{EXTEM}_{\mathrm{N}} \mathrm{MCF}$ and $\triangle \mathrm{MCE}$ using Spearman-Rho analysis.

The ability to predict thrombocytopenia was evaluated with receiver operating characteristics (ROC). $\mathrm{MCF}_{\text {EXTEM }}<49 \mathrm{~mm}, \mathrm{MCE}_{\text {EXTEM }}<93, \triangle \mathrm{MCF}<42 \mathrm{~mm}$ and $\triangle \mathrm{MCE}<90$ predicted thrombocytopenia $<60 \times 10^{9} / \mathrm{L}$ with a sensitivity of $90 \%$ and a specificity of $78 \%$ with a negative predictive value $>97 \%$ for all 4 parameters.

PLT in dogs correlated moderately but significantly with all evaluated ROTEM parameters. All parameters were able to rule out thrombocytopenia $<60 \times 10^{9} / \mathrm{L}$ with a high negative predictive value, while the sensitivity to predict thrombocytopenia was only moderate and the positive predictive value was low.

Canine, EXTEM, FIBTEM, ROTEM, Platelet component 


\title{
Correlation of rotational thromboelastometry (ROTEM) parameters with platelet count and their ability to predict thrombocytopenia in dogs ${ }^{\text {it }}$
}

\author{
Jennifer S. Turner ${ }^{\mathrm{a}}$, Annette P.N. Kutter ${ }^{\mathrm{b}}$, Nadja E. Sigrist ${ }^{\mathrm{a}, *}$ \\ ${ }^{a}$ Division of Critical Care Medicine, Department of Small Animals, Vetsuisse Faculty, University of Zurich, 8057 Zürich, Switzerland \\ ${ }^{\mathrm{b}}$ Section of Anesthesiology, Department for Diagnostics and Clinical Services, Vetsuisse Faculty, University of Zurich, 8057 Zürich, Switzerland
}

\section{A R T I C L E I N F O}

\section{Keywords:}

Canine

EXTEM

EIBTEM

Thromboelastography

Platelet component

\begin{abstract}
A B S T R A C T
The study objectivs were to evaluate the correlation between platelet count (PLT) and rotational thromboelastometry (ROTEM) parameters and to determine ROTEM cut-off values for identification of thrombocytopenia in dogs. Medical records of 113 dogs with concurrent EXTEM (ROTEM activated by proprietary tissue factor), FIBTEM (EXTEM with added cytochalasin D) analysis and PLT were retrospectively reviewed. Signalment, treatment prior to analysis, hematocrit (HCT), EXTEM/FIBTEM maximum clot firmness ( MCF $_{\text {EXTEM }}, M_{C F} F_{F I B T E M}$ ), EXTEM/FIBTEM maximum clot elasticity $\left(\mathrm{MCE}_{\mathrm{FXTEM}}, \mathrm{MCE}_{\mathrm{FIBTEM}}\right)$ and EXTEM maximum lysis $\left(\mathrm{ML}_{\mathrm{EXTEM}}\right.$ ) were extracted from patient records and ROTEM database. Delta $(\Delta)$ MCF was calculated as MCF $_{\text {EXTEM }}-\mathrm{MCF}_{\mathrm{FIBTEM}}$ and $\triangle \mathrm{MCE}$ as $\mathrm{MCE}_{\mathrm{EXTEM}}-\mathrm{MCE}_{\mathrm{FIBTEM}}$. The PLT was correlated to $\mathrm{MCF}_{\mathrm{EXTEM}}, \mathrm{MCE}_{\mathrm{EXTEM}}, \triangle \mathrm{MCF}$ and $\triangle \mathrm{MCE}$ using Spearman-Rho analysis. Correlations were further analyzed in thrombocytopenic dogs. The ability to predict thrombocytopenia was evaluated with receiver operating characteristics (ROC). Thirty-seven samples (32.7\%) showed thrombocytopenia $\left(<130 \times 10^{9} / \mathrm{L}\right)$ and 19 samples $(17 \%)$ severe thrombocytopenia $\left(<60^{*} \times 10^{9} / \mathrm{L}\right)$. The PLT significantly correlated with $\operatorname{MCF}_{\text {EXTEM }}(r=0.545, P<.001)$, MCE $_{\text {EXTEM }}(r=0.547, P<.001)$, $\triangle \mathrm{MCF}(r=0.441, P<.001)$ and $\triangle \mathrm{MCE}(r=0.559, P<.001) . \mathrm{MCF}_{\mathrm{EXTEM}}<49 \mathrm{~mm}, \mathrm{MCE}_{\mathrm{EXTEM}}<93$, $\triangle \mathrm{MCF}<42 \mathrm{~mm}$ and $\triangle \mathrm{MCE}<90$ predicted thrombocytopenia $<60 \times 10^{9} / \mathrm{L}$ with a sensitivity of $90 \%$ and a specificity of $78 \%$ with a negative predictive value $>97 \%$ for all 4 parameters. In conclusion, PLT in dogs correlated moderately but significantly with all evaluated ROTEM parameters. All parameters were able to rule out thrombocytopenia $<60 \times 10^{9} / \mathrm{L}$ with a high negative predictive value, while the sensitivity to predict thrombocytopenia was only moderate and the positive predictive value was low.
\end{abstract}

\section{Introduction}

Thromboelastic methods to determine coagulation status are a standard implement in human hospitals and are increasingly becoming available in clinical veterinary practice (Doderlein and Mischke, 2015; Sigrist et al., 2017; Goggs et al., 2018; Muri et al., 2018). Unlike conventional plasma-based coagulation tests, thromboelastic methods are performed in whole blood and give an almost instantaneous and global assessment of a patient's coagulation status from initial platelet-fibrin interactions to fibrinolysis (Solomon et al., 2012; Romlin et al., 2013). The two main thromboelastic devices used are rotational thromboelastometry (ROTEM) and thromboelastography (TEG). Both are point of care viscoelastic hemostasis tests that allow measurement of global clot formation and dissolution in whole blood (Whiting and DiNardo, 2014). With ROTEM, a cylindrical cup containing citrated whole blood and an activator remains fixed while a pin suspended on a ball- bearing mechanism initially oscillates through application of a constant force (Whiting and DiNardo, 2014). As the viscoelastic strength of the clot increases, the rotation of the pin is impeded and is detected optically (Whiting and DiNardo, 2014). Several coagulation activators are available by the manufacturer. The extrinsic activated assay (EXTEM) is activated by proprietary tissue factor whereas the intrinsic activated assay (INTEM) is activated by ellagic acid and phospholipid. The fibrin polymerization test (FIBTEM) is initiated by the same activator as the EXTEM analysis but additionally contains a platelet inhibitor (cytochalasin D) (Haas et al., 2014). The FIBTEM assay indicates the formation and stability of the fibrin clot (Lang et al., 2009).

Through computer analysis clot formation/dissolution kinetics and clot strength data can be generated (Whiting and DiNardo, 2014; Doderlein and Mischke, 2015). The main parameters measured and

\footnotetext{
This study was conducted at the Vetsuisse Faculty, University of Zurich, Switzerland.

* Corresponding author at: Department for Small Animals, Vetsuisse Faculty, University of Zurich, Winterthurerstr. 258c, 8057 Zurich, Switzerland.

E-mail address: nsigrist@vetclinics.uzh.ch (N.E. Sigrist).
}

https://doi.org/10.1016/j.rvsc.2019.08.007

Received 20 March 2019; Received in revised form 18 June 2019; Accepted 4 August 2019 0034-5288/ (c) 2019 Elsevier Ltd. All rights reserved. 
analyzed are the clotting time (CT) which describes the time until fibrin formation starts. The clot formation time (CFT) depends mainly on fibrinogen concentration and thrombocyte numbers and displays the kinetics of clot formation. The maximum clot firmness (MCF) describes the maximal strength of the fibrin/thrombocyte clot in $\mathrm{mm}$ while the maximum clot elasticity (MCE) reflects the force with which the clot resists rotation (Solomon et al., 2015). Fibrinolysis is assessed by maximum lysis (ML) in \% within 60 min of measurement.

While it is not possible to determine the platelet count (PLT) by ROTEM analysis, several ROTEM parameters have been evaluated for their correlation with PLT in people (Lang et al., 2009; Herbstreit et al., 2010; Solomon et al., 2011a; Haas et al., 2012; Keene et al., 2013; Lier et al., 2013; Solomon et al., 2015; Honickel and Grottke, 2016).

In people, subtracting FIBTEM MCF $\left(\mathrm{MCF}_{\mathrm{FIBTEM}}\right)$ or $\mathrm{MCE}\left(\mathrm{MCE}_{\mathrm{FIB}}\right.$ TEM) from EXTEM MCF ( MCF $_{\text {EXTEM }}$ ) or MCE (MCE platelet contribution ( $\triangle \mathrm{MCF}$ and $\triangle \mathrm{MCE}$ ) of the clot, which correlates with PLT (Lang et al., 2009; Solomon et al., 2011a; Dekker et al., 2014; Solomon et al., 2015). When ROTEM analysis is performed for other reasons or as a bedside analyzer, information regarding platelet contribution offers additional information and can guide additional diagnostic tests. In people with severe thrombocytopenia and acute bleeding disorders, the platelet contribution can be used for transfusion guidelines in that the contribution of platelets to clot elasticity determines the need for platelet concentrate transfusion (Solomon et al., 2015).

To our knowledge, ROTEM platelet contribution and its correlation with PLT has only been evaluated in one study of a population of dogs with renal disease (Falco et al., 2013). A moderate but significant correlation was described, but no further details were reported and other ROTEM parameters were not investigated (Falco et al., 2013).

The purpose of this study was to evaluate the correlation of PLT with $\mathrm{MCF}_{\text {EXTEM }}, \mathrm{MCE}_{\mathrm{EXTEM}}, \triangle \mathrm{MCF}$ and $\triangle \mathrm{MCE}$ in both healthy and sick dogs. A second goal was the determination of ROTEM cut-off values for the identification of thrombocytopenia. The hypothesis was that $\triangle \mathrm{MCF}$ $\triangle \mathrm{MCE}$, and possibly $\mathrm{MCF}_{\mathrm{EXTEM}}$ and $\mathrm{MCE}_{\mathrm{EXTEM}}$ alone correlate with PLT and can predict or rule out thrombocytopenia.

\section{Materials and methods}

The ROTEM database of the Small Animal Clinic, Vetsuisse Faculty of Zurich, was searched for dogs with simultaneous Ex-temS ${ }^{\circledR}$ (Werfen GmbH, Munich, Germany) and Fib-tems ${ }^{\oplus}$ (Werfen GmbH, Munich, Germany) analysis. Dogs were included for further analysis if a concurrent (within $2 \mathrm{~h}$ of the ROTEM analysis based on time noted in the database), automatic fluorescence flow cytometry PLT and HCT was available (Sysmex-XT 2000iV, Sysmex Cooperation, Kobe, Japan).

Only the first analysis from each case was included. Parameters obtained from patient records included sex, neutering status, age, weight, breed, medical treatment and transfusions administered prior to ROTEM analysis. Dogs were excluded if the above minimal database was not available.

Blood samples for ROTEM analysis (ROTEM-DeltaWerfen $\mathrm{GmbH}$, Munich, Germany) were analyzed according to an institutional protocol, which is based on manufacturer instructions and international guidelines (deLaforcade et al., 2014; Flatland et al., 2014; Hanel et al., 2014). Briefly, samples were rested at $37^{\circ} \mathrm{C}$ for at least $10 \mathrm{~min}$ and analyzed within $30 \mathrm{~min}$ using an automatic pipette. Tracings were run for $60 \mathrm{~min}$. All tracings were visually controlled for artifacts by one of the authors and suspicious tracings were reviewed by all 3 authors and excluded if an artefact could not be ruled out. Maximum clot elasticity was calculated as $100 \times \mathrm{MCF} / 100$ - MCF. An unmeasurable $\mathrm{MCF}_{\mathrm{FIBTEM}}$ (green line) was defined as $1 \mathrm{~mm}$. Delta MCF and $\triangle \mathrm{MCE}$ were calculated by subtracting $\mathrm{MCF}_{\mathrm{FIBTEM}} / \mathrm{MCE}_{\mathrm{FIBTEM}}$ from $\mathrm{MCF}_{\mathrm{EXTEM}} / \mathrm{MCE}_{\mathrm{EXTEM}}$, respectively. For analysis of subgroups, thrombocytopenia was defined as PLT below the reference interval $\left(130-394 \times 10^{9} / \mathrm{L}\right)$. Severe thrombocytopenia was defined as a PLT below $60 \times 10^{9} / \mathrm{L}$

\subsection{Statistical analysis}

Descriptive statistical analysis was performed using the statistical software program SPSS (SPSS, version 23, SPSS Inc., Chicago, IL) Normality of continuous data was tested using the Shapiro-Wilk test. Normally distributed data was presented as mean \pm SD while not normally distributed data was presented as median and range. Categorical data was described as frequencies. Thrombocytopenia was defined as PLT below the reference interval of the hospital's inhouse laboratory $\left(130-394 \times 10^{9} / \mathrm{L}\right)$. Correlation of PLT with $\mathrm{MCF}_{\mathrm{EXTEM}}$, $\mathrm{MCE}_{\mathrm{EXTEM}}, \triangle \mathrm{MCF}$ and $\triangle \mathrm{MCE}$ was analyzed using Spearman-Rho. A receiver operating characteristics (ROC) was performed with Graphpad Prism 7 (Prism 7.0, GraphPad Software Inc., La Jolla, CA) to determine the ability of $\mathrm{MCF}_{\mathrm{EXTEM}}, \mathrm{MCE}_{\mathrm{EXTEM}}, \triangle \mathrm{MCF}$ and $\triangle \mathrm{MCF}$ to detect thrombocytopenia $<130$ and $<60 \times 10^{9} / \mathrm{L}$. The area under the ROC curve was calculated and values from 0.7 to 0.79 were considered as fair, while values between 0.8 and 0.89 were defined as good results. To find the optimal cut-off value of $\mathrm{MCF}_{\mathrm{EXTEM}}, \mathrm{MCE}$ EXTEM, $\triangle \mathrm{MCF}$ and $\triangle \mathrm{MCE}$ to detect thrombocytopenia $<130$ and $<60 \times 10^{9} / \mathrm{L}$, the Youden's index was calculated. Significance was set at $P<.05$.

\section{Results}

Samples of 113 dogs evaluated between 2013 and 2016 were included. The median age of the population was 6.2 years (range, 0.4-13.3 years). Several breeds were identified with mixed breed $(n=21,16 \%)$, Beagle $(n=14,12 \%)$, Golden Retriever $(n=6,5 \%)$ and German Shepherd $(n=4,4 \%)$ being the most common. Fifty-four dogs (48\%) were female (33 spayed, 21 intact), 59 (62\%) were male ( 29 spayed, 30 intact). Treatments prior to ROTEM analysis included IV crystalloid fluids in 52/113 dogs (46\%), colloids in 15/113 (13.3\%), fresh frozen plasma in $12 / 113(11 \%)$ and packed red blood cells in 4 / 113 dogs (4\%). Eight dogs (7\%) had previously been treated with NSAIDs and 16/113 (14\%) had received tranexamic acid.

The median PLT was $200 \times 10^{9} / \mathrm{L}$ (range, $3-1304 \times 10^{9} / \mathrm{L}$ ). Thirtyseven $(33 \%)$ dogs were thrombocytopenic $\left(<130 \times 10^{9} / \mathrm{L}\right)$ with 19 $(17 \%)$ showing severe thrombocytopenia $\left(<60 \times 10^{9} / \mathrm{L}\right)$, while 66 (58\%) dogs had PLT within the reference interval and 10 (8.8\%) dogs showed thrombocytosis $\left(>394 \times 10^{9} / \mathrm{L}\right)$. Eight dogs $(7 \%)$ showed hyperfibrinolysis (maximum lysis $\geq 15 \%$ ). Characteristics of hematology and ROTEM-S parameters are summarized in Table 1.

Platelet count showed a moderate but significant correlation to $\mathrm{MCF}_{\text {EXTEM }}, \mathrm{MCE}_{\mathrm{EXTEM}}, \triangle \mathrm{MCF}$ and $\triangle \mathrm{MCE}$ (Table 2). The best correlation was obtained with $\triangle \mathrm{MCE}$ and exclusion of dogs with hyperfibrinolysis (Fig. 1). If only thrombocytopenic $\left(<130 \times 10^{9} / \mathrm{L}\right)$ dogs were analyzed, the correlation improved (Table 2). Excluding dogs with hyperfibrinolysis (ML $\mathrm{MLXTE}_{\mathrm{ETE}}>15 \%$ ) resulted in a strong correlation while exclusion of dogs that were treated with NSAIDS did not improve the correlation. Scatter-plots of platelet count versus MCF $_{\text {EXTEM }}$ and $\triangle \mathrm{MCF}$ showed a plateau of the curve at higher levels while the correlation of

Table 1

Hematocrit, platelet count, ex-tem $S^{\circledast}$ and fib-tem $S^{\circledast}$ parameters of 113 dogs with concurrent evaluation of ROTEM parameters and platelet count.

\begin{tabular}{|c|c|c|c|}
\hline Parameter (unit) & Mean \pm SD or median & Range & Reference interva \\
\hline Platelet count $\left(10^{9} / \mathrm{L}\right)$ & 200 & $3-1304$ & $130-394$ \\
\hline Hematocrit (\%) & $38 \pm 11$ & $11-71$ & $42-55$ \\
\hline $\mathrm{MCF}_{\text {EXTEM }}(\mathrm{mm})$ & $53 \pm 16$ & 9-95 & $32-65$ \\
\hline $\mathrm{MCE}_{\text {EXTEM }}$ & 122 & $10-1900$ & $45-142$ \\
\hline $\mathrm{ML}_{\text {EXTEM }}(\%)$ & 1 & $0-95$ & $0-12$ \\
\hline $\operatorname{MCF}_{\text {FIBTEM }}(\mathrm{mm})$ & 8 & $1-72$ & $2-9$ \\
\hline $\mathrm{MCE}_{\text {FIBTEM }}$ & 8 & $1-257$ & $2-10$ \\
\hline$\triangle \mathrm{MCF}(\mathrm{mm})$ & 47 & $-5-66$ & $27-50$ \\
\hline$\triangle \mathrm{MCE}$ & 113 & $-6-1643$ & $41-132$ \\
\hline
\end{tabular}

MCF, maximum clot firmness; MCE, maximum clot elasticity; ML, maximum lysis; $\triangle \mathrm{MCF}, \mathrm{MCF}_{\mathrm{EXTEM}}-\mathrm{MCF}_{\mathrm{FIBTEM}}$; $\triangle \mathrm{MCE}, \mathrm{MCE}_{\mathrm{EXTEM}}-\mathrm{MCE}_{\mathrm{FIBTEM}}$ 
Table 3

AUROC and cut-off values to detect thrombocytopenia $<60 \times 10^{9} / \mathrm{L}$ in 113 dogs.

\begin{tabular}{llllllll}
\hline & AUROC & Sensitivity (\%) & $95 \%$ CI & Specificity (\%) & $95 \%$ CI & Positive predictive value (\%) & Negative predictive value (\%) \\
\hline MCF $_{\text {EXTEM }} \leq 48 \mathrm{~mm}$ & 0.889 & 89.5 & $66.9-98.7$ & 77.7 & $67.9-85.6$ & 44.7 & 97.3 \\
MCE $_{\text {EXTEM }} \leq 92$ & 0.888 & 89.5 & $66.9-98.7$ & 78.7 & $69.1-86.5$ & 45.9 & 97.4 \\
$\Delta$ MCF $\leq 41 \mathrm{~mm}$ & 0.908 & 89.5 & $66.9-98.7$ & 77.7 & $67.9-85.6$ & 44.7 & 97.3 \\
$\Delta \mathrm{MCE}<90$ & 0.904 & 89.5 & $66.9-98.7$ & 77.7 & $67.9-85.6$ & 44.7 & 97.3 \\
\hline
\end{tabular}

AUROC, area under the receiver operating characteristics curve; CI, confidence interval; MCE, maximum clot elasticity; MCF, maximum clot firmness; $\triangle \mathrm{MCF}$, $\mathrm{MCF}_{\mathrm{EXTEM}}-\mathrm{MCF}_{\mathrm{FIBTEM}} ; \triangle \mathrm{MCE}, \mathrm{MCE}_{\mathrm{EXTEM}}-\mathrm{MCE}_{\mathrm{FIBTEM}}$.

Table 4

AUROC and cut-off values to detect thrombocytopenia $<130 \times 10^{9} / \mathrm{L}$ in 113 dogs.

\begin{tabular}{llllllll}
\hline Cut-off & AUROC & $\begin{array}{l}\text { Sensitivity } \\
(\%)\end{array}$ & $95 \% \mathrm{CI}$ & $\begin{array}{l}\text { Specificity } \\
(\%)\end{array}$ & $95 \% \mathrm{CI}$ & Positive predictive value (\%) & Negative predictive value (\%) \\
\hline $\mathrm{MCF}_{\text {EXTEM }} \leq 51 \mathrm{~mm}$ & 0.782 & 70.3 & $53-84.1$ & 75 & $63.7-84.2$ & 57.8 & 83.8 \\
$\mathrm{MCE}_{\text {EXTEM }}<105$ & 0.784 & 70.3 & $53-84.1$ & 76.3 & $65.2-85.3$ & 59.1 & 84.1 \\
$\Delta \mathrm{MCF} \leq 47 \mathrm{~mm}$ & 0.734 & 81.1 & $64.8-92$ & 56.6 & $44.7-67.9$ & 45.8 & 81.5 \\
$\Delta \mathrm{MCE}<100$ & 0.790 & 70.3 & $53-84.1$ & 76.3 & $65.2-85.3$ & 59.1 & 84.1 \\
\hline
\end{tabular}

AUROC, area under the receiver operating characteristics curve; CI, confidence interval; MCF, maximum clot firmness; MCE, maximum clot elasticity; $\triangle \mathrm{MCF}$, $\mathrm{MCF}_{\mathrm{EXTEM}}-\mathrm{MCF}_{\text {FIBTEM}}$; $\triangle \mathrm{MCE}$, MCE $\mathrm{EXTEM}_{\text {- }}-\mathrm{MCE}_{\mathrm{FIBTEM}}$.

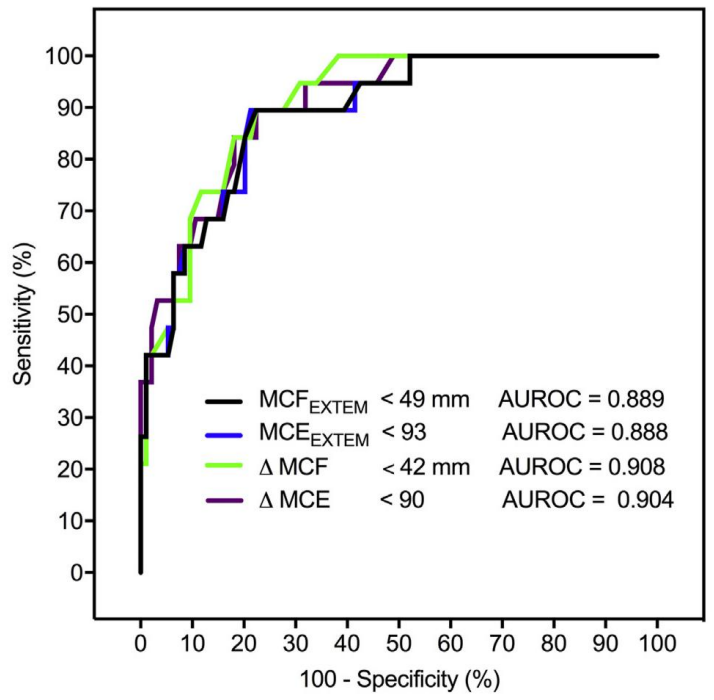

Fig. 2. Cut-off and AUROC of $\mathrm{MCF}_{\mathrm{FXTFM}}, \mathrm{MCE}_{\mathrm{EXTEM}}, \triangle \mathrm{MCF}$ and $\triangle \mathrm{MCE}$ to predict Thrombocytopenia $<60 \times 10^{9} / \mathrm{L}$ in dogs.

AUROC, area under the receiver operating characteristic curve; MCF, maximum clot firmness; $\mathrm{MCE}$, maximum clot elasticity; $\triangle \mathrm{MCF}, \mathrm{MCF}_{\mathrm{EXTEM}}-\mathrm{MCF}_{\mathrm{FIBTEM}}$; $\triangle \mathrm{MCE}, \mathrm{MCE}_{\mathrm{EXTEM}}-\mathrm{MCE}_{\mathrm{FIBTEM}}$

9-25 mm in people (Lang et al., 2005). In normo- or thrombocytotic dogs, the low "fibrin component" (low $\mathrm{MCF}_{\mathrm{FIBTEM}}$ and MCE $\mathrm{FIBTEM}_{\text {) does }}$ not contribute much to $\mathrm{MCF}_{\mathrm{EXTEM}}$ and $\mathrm{MCE}_{\mathrm{EXTEM}}$, leading to similar results of $\mathrm{MCF}_{\mathrm{EXTEM}}$ and $\mathrm{MCE}_{\mathrm{EXTEM}}$ and $\triangle \mathrm{MCF}$ and $\triangle \mathrm{MCE}$, respectively. The limited contribution of low $\mathrm{MCF}_{\mathrm{FIBTEM}}$ to $\mathrm{MCF}_{\mathrm{EXTEM}}$ has been described in cats (Marly-Voquer et al., 2017) and baboons (Schochl et al., 2012). However, the fibrin component of the clot reflected by $\mathrm{MCF}_{\mathrm{FI}}$

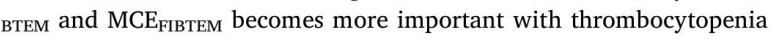
and lower $\mathrm{MCF}_{\mathrm{EXTEM}}$ and $\mathrm{MCE}_{\mathrm{EXTEM}}$ values, as shown in our subgroups of thrombocytopenic dogs. The correlation index remained moderate and significant using $\triangle \mathrm{MCF}$ or $\triangle \mathrm{MCE}$, while $\mathrm{MCF}_{\mathrm{EXTEM}}$ and MCE did no longer show a significant correlation with lower PLT. The use of $\triangle \mathrm{MCF}$ and $\triangle \mathrm{MCE}$ to estimate PLT is therefore expected to be superior to $\mathrm{MCF}_{\mathrm{EXTEM}}$ or MCE $\mathrm{MXTEM}_{\text {in }}$ thrombocytopenic dogs. In the current study, $\triangle \mathrm{MCF}$ and $\triangle \mathrm{MCE}$ yielded similar correlations at low PLTs. This

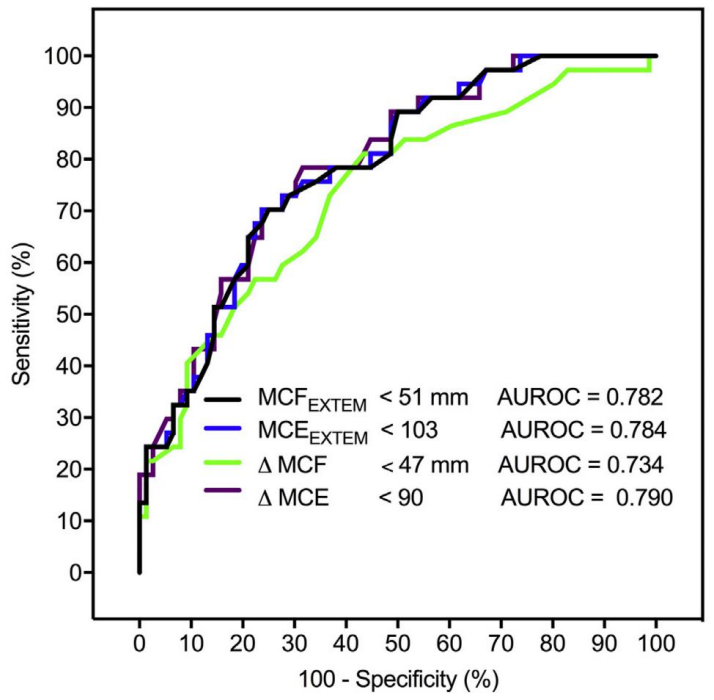

Fig. 3. Cut-off and AUROC of $\mathrm{MCF}_{\mathrm{EXTEM}}, \mathrm{MCE}_{\mathrm{EXTEM}}, \triangle \mathrm{MCF}$ and $\triangle \mathrm{MCE}$ to predict Thrombocytopenia $<130 \times 10^{9} / \mathrm{L}$ in dogs.

AUROC, area under the receiver operating characteristic curve; MCF, maximum clot firmness; MCE, maximum clot elasticity; $\triangle \mathrm{MCF}, \mathrm{MCF}_{\mathrm{EXTEM}}-\mathrm{MCF}_{\mathrm{FIBTEM}}$; $\triangle \mathrm{MCE}, \mathrm{MCE}_{\mathrm{EXTEM}}-\mathrm{MCE}_{\mathrm{FIBTEM}}$.

can be explained with the linear relationship of platelets with $\triangle \mathrm{MCF}$ in the lower range of the curve (Fig. 1).

Other reasons may account for the only moderate correlation between PLT and ROTEM parameters. Maximum clot firmness and elasticity quantify the function of fibrin, factor XIII and platelets. The firmness/elasticity of the clot is not only dependent on the number, but also on the function of the platelets. Although ROTEM is not sensitive to detect selective platelet inhibitors (Honickel and Grottke, 2016), we cannot exclude an effect on the relationship between PLT and evaluated ROTEM parameters as platelet function was not quantified in the current study. Treatment with NSAIDS may decrease MCF $_{\text {EXTEM (Brainard }}$ et al., 2007) while PLT should not be affected, however, exclusion of dogs treated with NSAIDS did not lead to a stronger correlation and we therefore conclude that this effect is minimal.

Exclusion of dogs with hyperfibrinolysis lead to a strong correlation. 
Table 2

Correlation of platelet count with $\mathrm{MCF}_{\mathrm{EXTEM}}, \mathrm{MCE}_{\mathrm{EXTEM}}, \triangle \mathrm{MCF}$ and $\triangle \mathrm{MCE}$ in 113 dogs and in subgroups.

\begin{tabular}{|c|c|c|c|c|}
\hline $\begin{array}{l}\text { Correlation of platelet } \\
\text { count with }\end{array}$ & $\mathrm{n}$ & Spearman $r$ & $\begin{array}{l}95 \% \text { confidence } \\
\text { interval }\end{array}$ & $\begin{array}{l}P \text {-value (two- } \\
\text { tailed) }\end{array}$ \\
\hline \multicolumn{5}{|l|}{ All dogs } \\
\hline $\mathrm{MCF}_{\text {EXTEM }}$ & 113 & 0.545 & 0.396 to 0.666 & $<0.0001$ \\
\hline MCE $_{\text {EXTEM }}$ & 113 & 0.547 & 0.399 to 0.668 & $<0.0001$ \\
\hline$\triangle \mathrm{MCF}$ & 113 & 0.441 & 0.274 to 0.582 & $<0.0001$ \\
\hline$\triangle \mathrm{MCE}$ & 113 & 0.559 & 0.413 to 0.677 & $<0.0001$ \\
\hline \multicolumn{5}{|c|}{ Thrombocytopenic dogs (platelet count $<130 \times 10^{9} / \mathrm{L}$ ) } \\
\hline $\mathrm{MCF}_{\text {EXTEM }}$ & 37 & 0.585 & 0.313 to 0.768 & $<0.0001$ \\
\hline MCE $_{\text {ЕХTEM }}$ & 37 & 0.589 & 0.318 to 0.77 & $<0.0001$ \\
\hline$\triangle \mathrm{MCF}$ & 37 & 0.682 & 0.451 to 0.82 & $<0.0001$ \\
\hline$\triangle \mathrm{MCE}$ & 37 & 0.649 & 0.40 to 0.807 & $<0.0001$ \\
\hline \multicolumn{5}{|c|}{ Severely thrombocytopenic dogs (platelet count $<60 \times 10^{9} / \mathrm{L}$ ) } \\
\hline $\mathrm{MCF}_{\text {EXTEM }}$ & 19 & 0.272 & -0.222 to 0.654 & 0.261 \\
\hline MCE $_{\text {EXTEM }}$ & 19 & 0.282 & -0.211 to 0.661 & 0.242 \\
\hline$\triangle \mathrm{MCF}$ & 19 & 0.510 & 0.0586 to 0.789 & 0.026 \\
\hline$\triangle \mathrm{MCE}$ & 19 & 0.488 & 0.0289 to 0.777 & 0.034 \\
\hline \multicolumn{5}{|c|}{ Exclusion of dogs with hyperfibrinolysis } \\
\hline $\mathrm{MCF}_{\mathrm{EXTEM}}$ & 105 & 0.602 & 0.4588 to 0.7141 & $<0.001$ \\
\hline $\mathrm{MCE}_{\text {EXTEM }}$ & 105 & 0.605 & 0.4626 to 0.7164 & $<0.001$ \\
\hline$\triangle \mathrm{MCF}$ & 105 & 0.484 & 0.3171 to 0.6219 & $<0.001$ \\
\hline$\triangle \mathrm{MCE}$ & 105 & 0.620 & 0.4813 to 0.7279 & $<0.001$ \\
\hline \multicolumn{5}{|c|}{ Exclusion of dogs with NSAID therapy } \\
\hline $\mathrm{MCF}_{\mathrm{EXTEM}}$ & 105 & 0.580 & 0.432 to 0.697 & $<0.001$ \\
\hline MCE $_{\text {EXTEM }}$ & 105 & 0.583 & 0.436 to 0.700 & $<0.001$ \\
\hline$\triangle \mathrm{MCF}$ & 105 & 0.472 & 0.303 to 0.612 & $<0.001$ \\
\hline$\triangle \mathrm{MCE}$ & 105 & 0.593 & 0.448 to 0.707 & $<0.001$ \\
\hline
\end{tabular}

$\mathrm{MCF}$, maximum clot firmness; MCE, maximum clot elasticity; $\triangle \mathrm{MCF}, \mathrm{MCF}_{\mathrm{Ex}}$ TEM $-\mathrm{MCF}_{\text {FIBTEM}}$; $\triangle \mathrm{MCE}, \mathrm{MCE}_{\mathrm{EXTEM}}-\mathrm{MCE}_{\mathrm{FIBTEM}}$.

platelet count to MCE and $\triangle \mathrm{MCE}$ was linear (Fig. 1).

The area under the receiver operating curve (AUROC), cut-off values, their sensitivity, specificity, positive and negative predictive values to detect severe thrombocytopenia and thrombocytopenia are
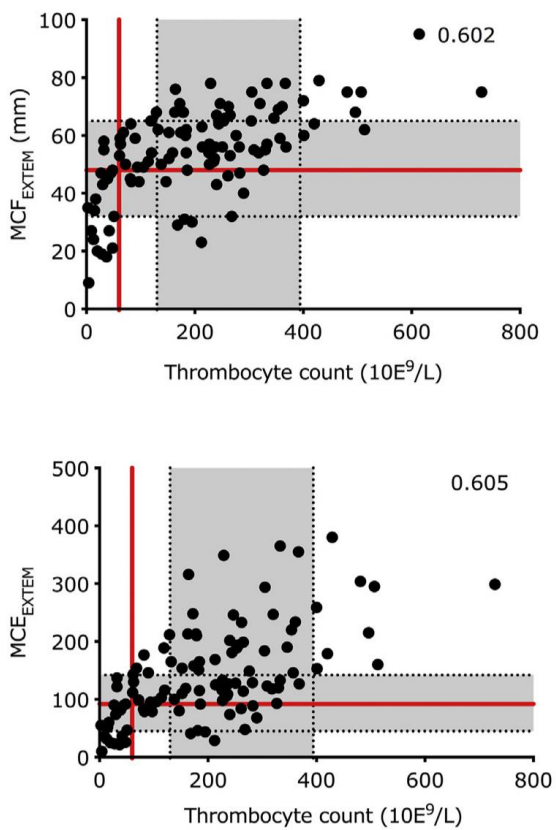

summarized in Tables 3 and 4, respectively. $\mathrm{MCF}_{\mathrm{EXTEM}} \mathrm{MCE}_{\text {EXTEM }}$ $\triangle \mathrm{MCF}$ and $\triangle \mathrm{MCE}$ had a large and similar AUROC to detect severe thrombocytopenia $<60 \times 10^{9} / \mathrm{L}$ with a negative predictive value $>$ 97\% for the best cut-off values in all 4 parameters (Table 3 and Fig. 2). The ability of ROTEM parameters to detect thrombocytopenia $<130$ $\times 10^{9} / \mathrm{L}$ was lower (Table 4 and Fig. 3 ).

\section{Discussion}

Our study results showed a moderate but significant correlation between PLT and all analyzed ROTEM parameters in dogs. All ROTEM parameters were able to exclude severe thrombocytopenia with a high negative predictive value.

A positive correlation of $\mathrm{MCF}_{\mathrm{EXTEM}}$ with PLT has been described in various studies in people includingchildren (Herbstreit et al., 2010; Haas et al., 2012; Keene et al., 2013; Lier et al., 2013; Honickel and Grottke, 2016) and was also identified in our canine population. As described in people (Solomon et al., 2015), we also report a nonlinear relationship between MCF and PLT in dogs; with MCF showing a plateau effect at high PLTs (Fig. 1). Maximum clot elasticity reflects the force with which the clot resists rotation within the device and MCE increases linearly with increasing PLT (Solomon et al., 2015). Maximum clot elasticity is therefore thought to better reflect PLT (Olde Engberink et al., 2014).

As both platelets and fibrin contribute to $\mathrm{MCF}_{\mathrm{EXTEM}} / \mathrm{MCE}_{\mathrm{EXTEM}}$, the contribution of platelets (platelet component) to clot strength can be determined by subtracting $\mathrm{MCF}_{\mathrm{FIBTEM}}$ or $\mathrm{MCE}_{\mathrm{FIBTEM}}$ from $\mathrm{MCF}_{\mathrm{EXTEM}}$ or

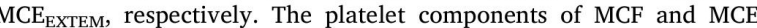
correlate even better to PLT in people (Lang et al., 2009; Solomon et al., 2011a,b, 2015). Again, $\triangle M C E$ is thought to be superior to $\triangle M C F$ as the relationship between clot firmness and PLT is nonlinear (Solomon et al., 2015). Our results in dogs do not indicate that the platelet component $\triangle \mathrm{MCF}$ or $\triangle \mathrm{MCE}$ correlates stronger with PLT than $\mathrm{MCF}_{\text {EXTEM }}$ or MCEEXTEM alone. This may be explained by the lower reference intervals of

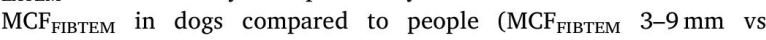
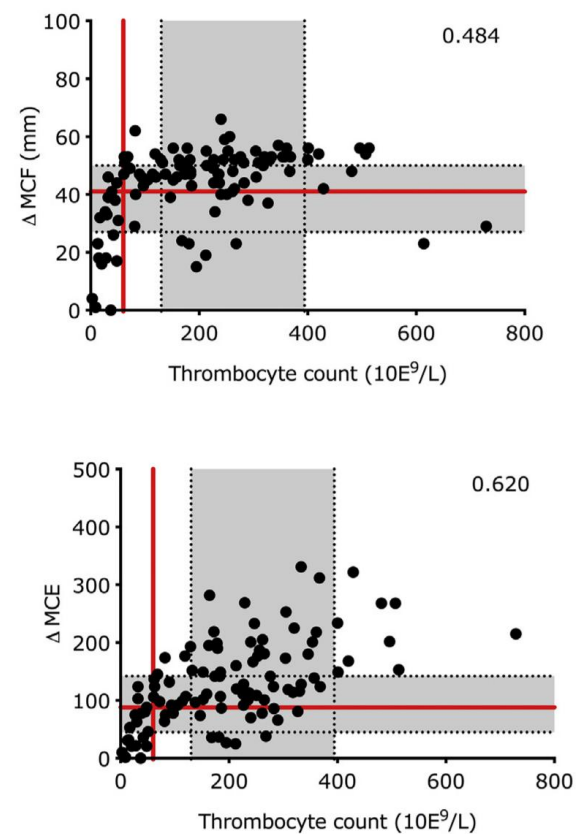

Fig. 1. Scatter plot of platelet count versus $\mathrm{MCF}_{\mathrm{EXTEM}}, \mathrm{MCE}_{\mathrm{EXTEM}}, \triangle \mathrm{MCF}$ and $\triangle \mathrm{MCE}$ in 105 dogs without hyperfibrinolysis. The graph was truncated at a platelet count of $800 \times 10^{\circ} / \mathrm{L}$ and MCE/AMCE 500. Shaded areas represent reference intervals. $\mathrm{MCF}$, maximum clot firmness; MCE, maximum clot elasticity; $\triangle \mathrm{MCF}, \mathrm{MCF}_{\mathrm{EXTEM}}-\mathrm{MCF}_{\mathrm{FIBTEM}}$; $\triangle \mathrm{MCE}, \mathrm{MCE}_{\mathrm{EXTEM}}-\mathrm{MCE}_{\mathrm{FIBTEM}}$ 
This is expected as hyperfibrinolysis could lead to a decrease in MCFEXTEM and MCE $\mathrm{EXTEM}_{\mathrm{E}}$ due to ongoing clot lysis and therefore also to a lower $\triangle \mathrm{MCF}$ and $\triangle \mathrm{MCE}$ (Levrat et al., 2008; Sigrist et al., 2018).

The FIBTEM assay contains cytochalasin D that is expected to inhibit any interaction of fibrinogen with platelets, however, a residual platelet effect on $\mathrm{MCF}_{\mathrm{FIBTEM}}$ has been described and becomes more important the more hypofibrinogenemic a patient is (Lang et al., 2009). Additionally, the HCT of a blood sample influences clot firmness and elasticity with anemic dogs having a hypercoagulable EXTEM or FIBTEM tracing due to a higher concentration of coagulation factors (Smith et al., 2012).

Of note, our institutional reference intervals for $\mathrm{MCF}_{\mathrm{EXTEM}}$ and MCE $_{\text {EXTEM }}$ are lower than those for MCF $_{\text {INTEM }}$ and MCE INTEM. In people (Lang et al., 2005) and cats (Marly-Voquer et al., 2017), the reference interval of those parameters is very similar. As $\mathrm{MCF}_{\text {INTEM }} / \mathrm{MCE}_{\text {INTEM }}$ are higher than $\mathrm{MCF}_{\mathrm{EXTEM}} / \mathrm{MCE}_{\mathrm{EXTEM}}$, they may better reflect PLT. Our database did not contain enough INTEM data to be able to address this question and further studies are needed to investigate possible better parameters such as MCF $_{\text {INTEM }} /$ MCE $_{\text {INTEM }}$ to estimate PLT in dogs. With the current results we recommend using $\triangle \mathrm{MCE}$ and exclude samples with hyperfibrinolysis, as this showed a strong correlation over various PLT.

The AUROC of all evaluated ROTEM parameters to detect severe thrombocytopenia $<60 \times 10^{9} / \mathrm{L}$ was high and $\triangle \mathrm{MCF}$ or $\triangle \mathrm{MCE}$ were not superior to $\mathrm{MCF}_{\mathrm{EXTEM}}$ or $\mathrm{MCE}_{\mathrm{EXTEM}}$. While all evaluated cut-off values showed a good sensitivity, the specificity to detect severe thrombocytopenia $<60 \times 10^{9} / \mathrm{L}$ was only moderate. The low positive predictive value and the fact that all cut-off values are in the middle to upper range of the reference interval limits the clinical utility to predict thrombocytopenia. However, all 4 evaluated parameters had a high negative predictive value of $97 \%$ and the reported cut-off values can be used to rule out thrombocytopenia $<60 \times 10^{9} / \mathrm{L}$. Dogs with values lower than the cut-off values should undergo further testing as accurate PLT are clinically relevant in cases with suspected low numbers. While PLTs can easily be estimated by manual evaluation of a blood smear in humans, the platelet estimation in canine blood smears can vary significantly (Paltrinieri et al., 2018). Determination of PLT is therefore indicated but a reliable hematology analyzer may not be available in an emergency situation and may take longer. Using a point-of-care device such as ROTEM can - if available - rule out clinically significant thrombocytopenia until absolute PLT is available.

The main advantage performing ROTEM analysis rather than manual platelet count is concurrent diagnosis of other hemostatic abnormalities such as hypofibrinogenemia, clotting factor deficiency or hyperfibrinolysis. ROTEM analysis further allows the identification of clot strength in thrombocytopenic dogs, eg a strong FIBTEM may lead to normal clot formation despite low platelet count and therefore not require treatment with platelet transfusion. Platelet count alone does not always correlate with bleeding symptomatology and may be a worse predictor of bleeding than viscoelastic tests in dogs and people (O'Marra et al., 2012; Bucknoff et al., 2014; Greene et al., 2014). In the current retrospective study, evaluation of PLT and ROTEM parameters to predict bleeding was not performed.

\subsection{Limitations}

Being a retrospective study, several limitations need to be discussed. First, the study population is heterogenous as any dog with concurrent determination of ROTEM and PLT was eligible to enter the study and the number was too small to evaluate subgroups with different hemostatic disorders. Additionally, the study population included only 19 patients with a very low PLT and the results to identify thrombocytopenia $<60 \times 10^{9} / \mathrm{L}$ should be interpreted with caution. Despite the low number of thrombocytopenic dogs, our results show that the evaluated ROTEM parameters can be used to rule out severe thrombocytopenia. Third, a time difference between tests of $120 \mathrm{~min}$ was allowed due to different locations (hospital laboratory for PLT and onsite performance of ROTEM analysis). However, every effort was made to choose only concurrent blood samples and samples were excluded if patient records suggested that two different blood samples were analyzed within this time frame. Additionally, the storage time of blood samples may have influenced results as prolonged storage time can have a profound impact on ROTEM results depending on the activator with a shift towards hypercoagulability (Smith et al., 2010). However, modern activated tests as used in the current study are less dependent on storing time than native samples (Smith et al., 2010). As $88 \%$ of samples were analyzed within $60 \mathrm{~min}$, we further do not think that time significantly influenced results. Handling and storage time of each sample may have varied due to the retrospective nature of the study, but our ROTEM assays should be performed following institutional guidelines based on manufacturer instructions and international guidelines (deLaforcade et al., 2014; Flatland et al., 2014; Hanel et al., 2014). Additionally, small differences in handling and storage time mimic the clinical situation and were therefore accepted. Artifacts due to inappropriate test performance was excluded by visual evaluation of all curves. Colloid solutions administered in 13 dogs may have influenced the results due to weakening of the $\mathrm{MCF}_{\mathrm{FIBTEM}}$. However, the platelet component should not have been affected (Weiss et al., 2010; Hartog et al., 2011; Falco et al., 2012; Wurlod et al., 2015) and the study sample size was considered too small to analyze each subgroup separately.

\section{Conclusions}

Platelet count in dogs correlated moderately but significantly with all evaluated ROTEM parameters. The correlations using $\triangle \mathrm{MCF}$ and $\triangle \mathrm{MCE}$ were superior to $\mathrm{MCF}_{\mathrm{EXTEM}}$ and $\mathrm{MCE}_{\mathrm{EXTEM}}$ in thrombocytopenic dogs and the correlation became strong if dogs with hyperfibrinolysis were excluded. All parameters were able to rule out thrombocytopenia $<60 \times 10^{9} / \mathrm{L}$ with a high negative predictive value while the positive predictive value was low.

\section{Declaration of Competing Interest}

This research did not receive any specific grant from funding agencies in the public, commercial, or not-for-profit sectors and the authors declare no conflict of interest.

\section{Acknowledgement}

The authors would like to thank Dr. Sonja Hartnack for help with statistical analysis.

\section{References}

Brainard, B.M., Meredith, C.P., Callan, M.B., Budsberg, S.C., Shofer, F.S., Driessen, B., Otto, C.M., 2007. Changes in platelet function, hemostasis, and prostaglandin expression after treatment with nonsteroidal anti-inflammatory drugs with various cyclooxygenase selectivities in dogs. Am. J. Vet. Res. 68, 251-257.

Bucknoff, M.C., Hanel, R.M., Marks, S.L., Motsinger-Reif, A.A., Suter, S.E., 2014. Evaluation of thromboelastography for prediction of clinical bleeding in thromboEvaluation of thromboelastography for prediction of clinical bleeding in thrombo-
cytopenic dogs after total body irradiation and hematopoietic cell transplantation. cytopenic dogs after total body
Am. J. Vet. Res. $75,425-432$.

Dekker, S.E., Viersen, V.A., Duvekot, A., de Jong, M., van den Brom, C.E., van de Ven, P.M., Schober, P., Boer, C., 2014. Lysis onset time as diagnostic rotational thromP.M., Schober, P., Boer, C., 2014. Lysis onset time as diagnostic rotational throm-
boelastometry parameter for fast detection of hyperfibrinolysis. Anesthesiology. 121 , 89-97.

deLaforcade, A., Goggs, R., Wiinberg, B., 2014. Systematic evaluation of evidence on veterinary viscoelastic testing part 3: assay activation and test protocol. J. Vet. Emerg. Crit. Care 24, 37-46.

Doderlein, E., Mischke, R., 2015. Reference intervals for thromboelastometry with the ROTEM delta in cats. Res. Vet. Sci. 100, 271-276.

Falco, S., Bruno, B., Maurella, C., Bellino, C., D’Angelo, A., Gianella, P., Tarducci, A. Zanatta, R., Borrelli, A., 2012. In vitro evaluation of canine hemostasis following dilution with hydroxyethyl starch $(130 / 0.4)$ via thromboelastometry. J. Vet. Emerg Crit. Care 22, 640-645.

Falco, S., Zanatta, R., Bruno, B., Maurella, C., Scalone, A., Tarducci, A., Borrelli, A., 2013 
Thromboelastometry used for evaluation of blood coagulability in dogs with kidney diseases. Acta Vet. Brno 82, 209-214.

Flatland, B., Koenigshof, A.M., Rozanski, E.A., Goggs, R., Wiinberg, B., 2014. Systemati evaluation of evidence on veterinary viscoelastic testing part 2: sample acquisition and handling. J. Vet. Emerg. Crit. Care 24, 30-36.

Goggs, R., Borrelli, A., Brainard, B.M., Chan, D.L., de Laforcade, A., Goy-Thollot, I., Jandrey, K.E., Kristensen, A.T., Kutter, A., Marschner, C.B., Rannou, B., Sigrist, N., Wagg, C., 2018. Multicenter in vitro thromboelastography and thromboelastometry standardization. J. Vet. Emerg. Crit. Care 28, 201-212.

Greene, L.A., Chen, S., Seery, C., Imahiyerobo, A.M., Bussel, J.B., 2014. Beyond the platelet count: immature platelet fraction and thromboelastometry correlate with bleeding in patients with immune thrombocytopenia. Br. J. Haematol. 166, 592-600.

Haas, T., Spielmann, N., Mauch, J., Madjdpour, C., Speer, O., Schmugge, M., Weiss, M., 2012. Comparison of thromboelastometry (ROTEM ${ }^{\circledR}$ ) with standard plasmatic coagulation testing in paediatric surgery. Br. J. Anaesth. 108, 36-41.

Haas, T., Goobie, S., Spielmann, N., Weiss, M., Schmugge, M., 2014. Improvements in patient blood management for pediatric craniosynostosis surgery using a ROTEM ${ }^{\oplus}$ -assisted strategy - feasibility and costs. Paediatr. Anaesth. 24, 774-780.

Hanel, R.M., Chan, D.L., Conner, B., Gauthier, V., Holowaychuk, M., Istvan, S., Walker, J.M., Wood, D., Goggs, R., Wiinberg, B., 2014. Systematic evaluation of evidence on veterinary viscoelastic testing part 4: definitions and data reporting. J. Vet. Emerg. Crit. Care 24, 47-56

Hartog, C.S., Reuter, D., Loesche, W., Hofmann, M., Reinhart, K., 2011. Influence of hydroxyethyl starch (HES) 130/0.4 on hemostasis as measured by viscoelastic device analysis: a systematic review. Intensive Care Med. 37, 1725-1737.

Herbstreit, F., Winter, E.M., Peters, J., Hartmann, M., 2010. Monitoring of haemostasis in liver transplantation: comparison of laboratory based and point of care tests. Anaesthesia. 65, 44-49.

Honickel, M., Grottke, O., 2016. Rotational thromboelastometry for the diagnosis of coagulation disorders. Med. Klin., Intensivmed. Notfallmed.

Keene, D.D., Nordmann, G.R., Woolley, T., 2013. Rotational thromboelastometry-guided trauma resuscitation. Curr. Opin. Crit. Care 19, 605-612.

Lang, T., Bauters, A., Braun, S.L., Potzsch, B., von Pape, K.W., Kolde, H.J., Lakner, M., 2005. Multi-centre investigation on reference ranges for ROTEM thromboelastometry. Blood Coagul. Fibrinolysis 16, 301-310.

Lang, T., Johanning, K., Metzler, H., Piepenbrock, S., Solomon, C., Rahe-Meyer, N., Tanaka, K.A., 2009. The effects of fibrinogen levels on thromboelastometric variables in the presence of thrombocytopenia. Anesth. Analg. 108, 751-758.

Levrat, A., Gros, A., Rugeri, L., Inaba, K., Floccard, B., Negrier, C., David, J.S., 2008. Evaluation of rotation thrombelastography for the diagnosis of hyperfibrinolysis in trauma patients. Br. J. Anaesth. 100, 792-797.

Lier, H., Vorweg, M., Hanke, A., Gorlinger, K., 2013. Thromboelastometry guided therapy of severe bleeding. Essener Runde algorithm. Hamostaseologie. 33, 51-61.

Marly-Voquer, C., Riond, B., Jud Schefer, R., Kutter, A.P., 2017. Reference values for rotational thromboelastometry (ROTEM) in clinically healthy cats. J. Vet. Emero. Crit Care 27, 185-192.

Muri, B., Schmierer, P., Schwarz, A., Sigrist, N., 2018. Hyperfibrinolysis diagnosed with rotational thromboelastometry and treated with tranexamic acid in a dog with acut traumatic coagulopathy. Schweiz. Arch. Tierheilkd. 160, 227-233.
Olde Engberink, R.H.G., Kuiper, G.J.A.J.M., Wetzels, R.J.H., Nelemans, P.J., Lance, M.D. Beckers, E.A.M., Henskens, Y.M.C., 2014. Rapid and correct prediction of thrombocytopenia and hypofibrinogenemia with rotational thromboelastometry in cardiac surgery. J. Cardiothorac. Vasc. Anesth. 28, 210-216.

O'Marra, S.K., Shaw, S.P., deLaforcade, A.M., 2012. Investigating hypercoagulability during treatment for immune-mediated thrombocytopenia: a pilot study. J. Vet. Emerg. Crit. Care 22, 126-130

Paltrinieri, S., Paciletti, V., Zambarbieri, J., 2018. Analytical variability of estimated platelet counts on canine blood smears. Vet. Clin. Pathol. 47, 197-204.

Romlin, B.S., Wahlander, H., Synnergren, M., Baghaei, F., Jeppsson, A., 2013. Earlier detection of coagulopathy with thromboelastometry during pediatric cardiac surgery: a prospective observational study. Paediatr. Anaesth. 23, 222-227.

Schochl, H., Solomon, C., Laux, V., Heitmeier, S., Bahrami, S., Redl, H., 2012. Similarities in thromboelastometric (ROTEM ${ }^{\oplus}$ ) findings between humans and baboons. Thromb. Res. 130, e107-e112.

Sigrist, N.E., Hofer-Inteeworn, N., Jud Schefer, R., Kuemmerle-Fraune, C., Schnyder, M. Kutter, A.P.N., 2017. Hyperfibrinolysis and hypofibrinogenemia diagnosed with rotational thromboelastometry in dogs naturally infected with angiostrongylus vasorum. J. Vet. Intern. Med. 31, 1091-1099.

Sigrist, N.E., Schefer, R.J., Kutter, A.P.N., 2018. Characteristics of hyperfibrinolysis in dogs and cats demonstrated by rotational thromboelastometry (ROTEM). Vet. J. 242, 67-73.

Smith, S.A., McMichael, M., Galligan, A., Gilor, S., Hoh, C.M., 2010. Clot formation in canine whole blood as measured by rotational thromboelastometry is influenced by sample handling and coagulation activator. Blood Coagul. Fibrinolysis 21, 692-702.

Smith, S.A., McMichael, M.A., Gilor, S., Galligan, A.J., Hoh, C.M., 2012. Correlation of hematocrit, platelet concentration, and plasma coagulation factors with results of thromboelastometry in canine whole blood samples. Am. J. Vet. Res. 73, 789-798.

Solomon, C., Rahe-Meyer, N., Sorensen, B., 2011a. Fibrin formation is more impaired than thrombin generation and platelets immediately following cardiac surgery. Thromb. Res. 128, 277-282

Solomon, C., Traintinger, S., Ziegler, B., Hanke, A., Rahe-Meyer, N., Voelckel, W., Schochl, H., 2011b. Platelet function following trauma. A multiple electrode aggregometry study. Thromb. Haemost. 106, 322-330.

Solomon, C., Sorensen, B., Hochleitner, G., Kashuk, J., Ranucci, M., Schochl, H., 2012. Comparison of whole blood fibrin-based clot tests in thrombelastography and thromboelastometry. Anesth. Analg. 114, 721-730.

Solomon, C., Ranucci, M., Hochleitner, G., Schochl, H., Schlimp, C.J., 2015. Assessing the methodology for calculating platelet contribution to clot strength (platelet component) in thromboelastometry and thrombelastography. Anesth. Analg. 121, 868-878.

Weiss, G., Lison, S., Spannagl, M., Heindl, B., 2010. Expressiveness of global coagulation parameters in dilutional coagulopathy. Br. J. Anaesth. 105, 429-436.

Whiting, D., DiNardo, J.A., 2014. TEG and ROTEM: technology and clinical applications. Am. J. Hematol. 89, 228-232.

Wurlod, V.A., Howard, J., Francey, T., Schweighauser, A., Adamik, K.N., 2015 Comparison of the in vitro effects of saline, hypertonic hydroxyethyl starch, hypertonic saline, and two forms of hydroxyethyl starch on whole blood coagulation and platelet function in dogs. J. Vet. Emerg. Crit. Care 25, 474-487. 


\section{Curriculum Vitae}

Jennifer Turner

12.05.1982

Wetzikon $\mathrm{ZH}$

$\mathrm{CH}$

Kölliken AG

08/1987 - 07/1990

$08 / 1990-07 / 1995$

$08 / 1995-07 / 1998$

$08 / 1998-09 / 2002$

06.09.2002

$09 / 2002-08 / 2008$

29.08.2008

$08 / 2016$

- $12 / 2019$
Primarschule, Paignton, UK

Primarschule, Olten, $\mathrm{CH}$

Gymnasium, Olten, $\mathrm{CH}$

Gymnasiale Maturitätsschule, Kantonsschule Olten, $\mathrm{CH}$

Matura, Kantonsschule Olten, $\mathrm{CH}$

Studium Veterinärmedizin, Universität Bern, $\mathrm{CH}$

Abschlussprüfung vet.med., Universität Bern, $\mathrm{CH}$

09/2008 - 08/2012 Assistenzärztin, Tierklinik 24 AG, Staffelbach AG, CH

01/2013 - 12/2014 Assistenzärztin, cand. FVH, BolligerTschuor AG Fachtierärzte für Kleintiere, Oftringen AG, CH

01/2015 - 07/2016 Internship Kleintierchirurgie, Tierspital Zürich, CH

08/2016 - 12/2016 Assistenzärztin Notfall, Tierspital Zürich, CH

06/2017 - 11/2018 Tierärztin FVH, Tierklinik AW AG, Oberentfelden AG, CH

12/2018 - heute Tierärztin FVH, Tierklinik Sonnenhof AG, Derendingen SO, CH 